DOI 10.37882/2223-2982.2020.04-2.22

\title{
СОЦИАЛИЗАЦИЯ УЧАЩИХСЯ С ОСОБЫМИ ОБРАЗОВАТЕЛЬНЫМИ ПОТРЕБНОСТЯМИ КАК СОЦИАЛЬНО-ПЕДАГОГИЧЕСКАЯ ПРОБЛЕМА
}

\section{SOCIALIZATION OF PUPILS WITH SPECIAL EDUCATIONAL NEEDS AS SOCIAL- PEDAGOGICAL PROBLEM}

\section{O. Kotikova}

Summary: This article presents the analysis of social-pedagogical aspects of socialization of pupils with special educational needs, which are defined as a heterogenous group of pupils. The article provides the results of the research of a heterogenous group of pupils, according to certain factors of socialization, as well as suggests conditions, necessary for their socialization.

Keywords: socialization, pupils with special educational needs, heterogeneous group of pupils.

\section{Ввехение}

И зучение проблемы социализации обучающихся их интеграция обусловлено изменениями социокультурной ситуации, характеризующейся процессами глобализации и массовой миграции населения, стремительным переходом к цифровому обществу, усложнением социальной среды (рост асоциальных влияний), снижением воспитательного потенциала семьи. Научный интерес к процессу социализации не только как к явлению социально-психологическому, но и как к педагогическому настоятельная реальность нового времени. Согласно стратегии развития сферы воспитания подрастающего поколения в Российской Федерации на период до 2025 года, создание условий для успешной социализации учащихся выделяется как стратегический общенациональный приоритет, требующий консолидации усилий различных институтов гражданского общества [4]. Необходимость формирования в условиях образовательного учреждения системы выявления, поддержки и развития способностей и талантов учащихся, обеспечивающей самоопределение и профессиональную ориентацию всех обучающихся, в том числе имеющих особые образовательные потребности, определена в национальном проекте «Образование», в части подпроекта «Успех каждого ребенка» [4].

\section{Изложение основного материала}

Целью нашей статьи является обоснование теорети-

\author{
Котикова Оксана Валентиновна \\ Аспирант, учитель, Санкт-Петербургская академия \\ постдипломного образования \\ kotikox@mail.ru
}

Аннотация: В статье анализируются социально-педагогические аспекты процесса социализации учащихся с особыми образовательными потребностями. Уточнено понятие «учащиеся с особыми образовательными потребностями» как гетерогенная группа обучающихся. Автором приведены результаты исследования гетерогенной группы обучающихся по отдельным факторам социализации, сформулированы необходимые условия обеспечения социализации учащихся с особыми образовательными потребностями в школе.

Ключевые слова: социализация, учащиеся с особыми образовательными потребностями, гетерогенная группа обучающихся. ческого аспекта процесса социализации в педагогике и анализ условий социализации учащихся с особыми образовательными потребностями в период обучения в школе.

В педагогической науке социализация рассматривается прежде всего в контексте процесса воспитания. В.А. Сухомлинский одним из первых поднял проблему социализации ребенка в педагогике. «Общественная сущность человека проявляется в его отношениях, связях, взаимоотношениях с другими людьми. Познавая мир и себя как частицу мира, вступая в разнообразные отношения с людьми, отношения, удовлетворяющие его материальные и духовные потребности, ребенок включается в общество, становится его членом. Этот процесс приобщения личности к обществу и, следовательно, процесс формирования личности ученые называют социализацией» $[7$, с. 51].

Социально-педагогическому аспекту проблемы социализации посвящены работы: Г.М. Андреевой, А.В. Мудрика, Е.И. Исаева, В.И. Слободчикова, Н.Ф. Головановой, Л. С. Выгодского, А.Н. Леонтьева, А.С. Алексеевой, П.П. Блонского, А.С. Макаренко, Б.Д. Парыгина, В.А. Сухомлинского, Л.И. Новиковой, С.Т. Шацкого и др.

Е.И. Исаев и В.И. Слободчиков предлагают рассматривать социализацию как «процесс образования, включающий в себя, как усвоение индивидом социального опыта путем вхождения в социальную среду и систему 
социальных связей, так и активное воспроизводство этой системы индивидом в своей жизнедеятельности; как процесс и результат спонтанного усвоения и воспроизводства социального опыта как опыта совместной жизнедеятельности людей, опыта общения и взаимодействия между людьми» [1, с. 427].

В процессе социализации среда выступает как условие становления личности, компонент симбиотического единства личности и общества, поле значений, смыслов, открываемых личностью в процессе деятельности с другими людьми, оказывающих на нее социализирующее влияние. В этой связи необходимо отметить, что социализация ребенка протекает под действием разнообразных условий и факторов, которые в той или иной степени оказывают влияние на его развитие. Отсюда следует, что социализация может происходить стихийно, когда человек подвергается неконтролируемому воздействию разнонаправленных обстоятельств жизни, а также в социально контролируемых условиях, организуемых для развития человека, что происходит в процессе воспитания. Область школьного образования имеет своей границей выход ребенка в «большой социум». Становясь школьником, ребенок не прекращает участвовать в жизни сообщества, не изолирован в границах образовательного учреждения и школа должна отвечать на те вызовы, которые предъявляются со стороны социума.

Таким образом, в педагогике социализация рассматривается в контексте образовательного процесса, следовательно, создания педагогических условий, направленных на преобразование качеств и поведения личности, способствующих ее развитию и включению в общественные отношения.

Несмотря на то, что в отечественной педагогике накоплен огромный опыт воспитательной работы, в том числе направленной на социализацию обучающихся, учащиеся с особыми образовательными потребностями относятся к группе риска, наиболее подверженной влиянию десоциализирующих факторов.

Современное понимание особых образовательных потребностей связано с понятием гетерогенности, что явилось следствием переосмысления отношения к гетерогенным группам населения в обществе, признания не только равенства их прав, но и обязанности обеспечить им наравне с другими людьми возможности в получении образования. На всемирной конференции по образованию при патронаже ЮНЕСКО к категории обучающихся, имеющих особые образовательные потребности были отнесены дети с «умственными и физическими недостатками, одаренные дети, беспризорные и работающие дети, дети из отдаленных районов или относящиеся к кочевым народностям, дети, относящиеся к языковым и культурным меньшинствам и дети из менее благопри- ятных и маргинализированных районов или групп населения» [5].

Проблематике образования детей с особыми образовательными потребностями, как гетерогенной группы обучающихся посвящены работы Д. Гжибовской, О.Н Крыловой, Е.В.Иванова, М. Нвое Рашед, Н.А Шайдоровой, И. Г. Шамсутдиновой, Н. В. Кравченко и др. Образовательные потребности, как педагогическую проблему рассматривали Г.И Щукина, Л.И. Божович, О. С. Астерминова., О.Н. Крылова и др. В контексте педагогики потребность в образовании становится мотивом, который побуждает учащегося к направленной деятельности, имеющей своей целью не только приобретение новых знаний и умений, получение нового опыта, но и возможность самореализации и получения жизненно необходимых знаний.

Для определения условий, обеспечивающих социализацию учащихся с особыми образовательными потребностями в образовательном учреждении, нам необходимо было исследовать личностные характеристики представителей гетерогенной группы обучающихся, оценку учащимися своего поведения, успешности в школе и в общении со сверстниками, степень уверенности в себе и удовлетворенности положением в семье. Исследование проводилось на базе трех школ Санкт-Петербурга. Гетерогенную группу респондентов составила выборка из 150 обучающихся 7-х классов государственных бюджетных общеобразовательных учреждений, где $11 \%$-обучающиеся с ОВ3, 25\% - одаренные учащиеся, 9\% - дети-мигранты, $18 \%$ - социально-неблагополучные учащиеся и 37 \% - нормотипичные школьники. Для исследования нами была адаптирована методика, разработанная американскими психологами Е. Пирсом, Д. Харрисом, адаптированная А.М. Прихожан к российской ментальности [3]. Исследование отдельных факторов позволило оценить способность учащихся с особыми образовательными потребностями сохранять свою личную идентичность, принимая различные социальные роли в семье и школе.

Сравнительный анализ результатов анкетирования по отдельным факторам самосознания личности позволил выделить среди учащихся с особыми образовательными потребностями проблемные области (Рис 1).

На гистограмме представлен ряд факторов, где показатели у групп учащихся с особыми образовательными потребностями коррелируются с показателями контрольный группы нормотипичных школьников. На основании соотнесения данных, нами были сделаны выводы по отдельным факторам, которые могут затруднять процесс социализации и требуют более пристального внимания со стороны педагогических работников. По такому фактору, как «ситуация в школе», учащиеся с особыми образовательными потребностями испытывают 


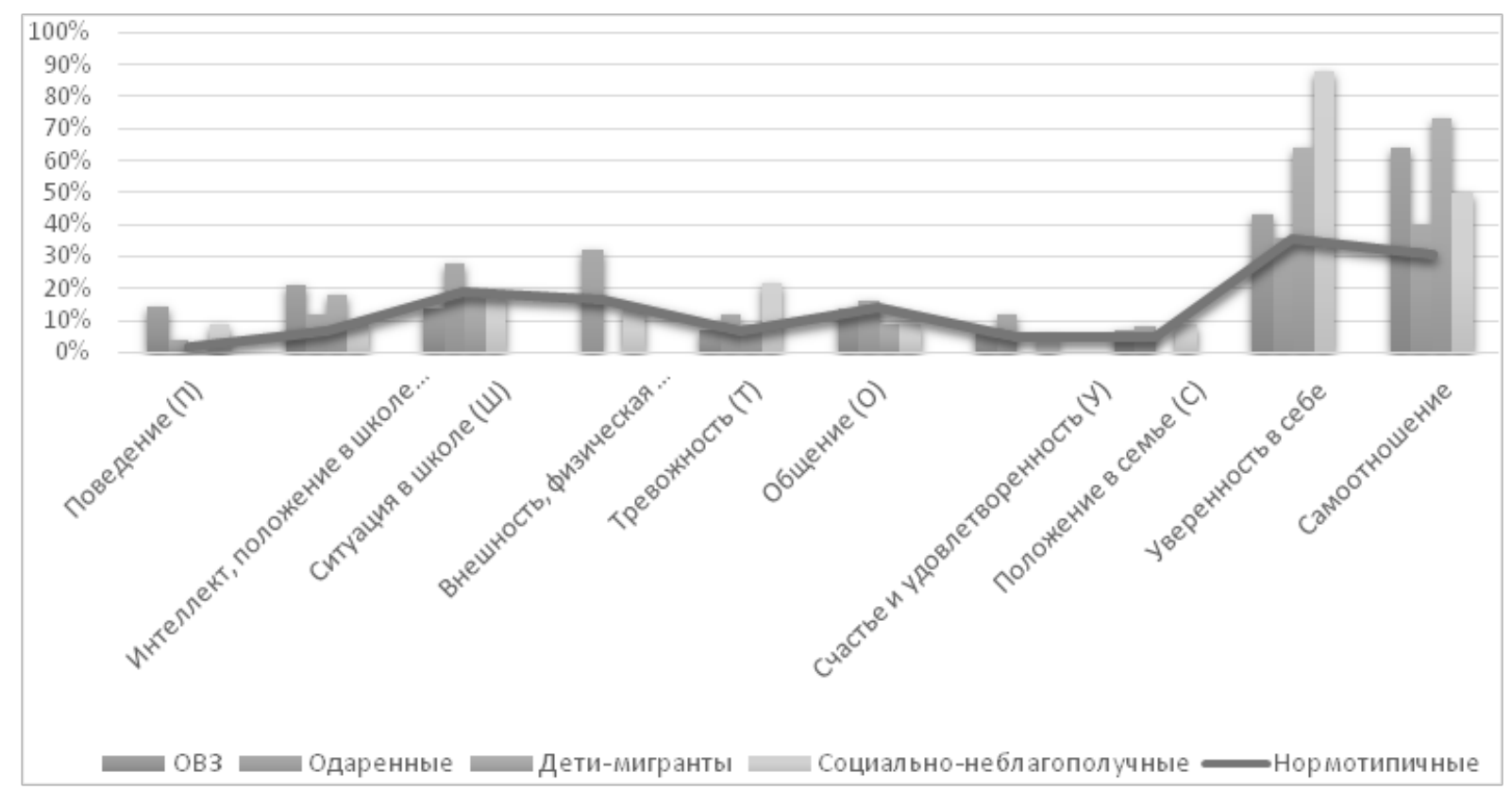

Рисунок 1

меньше сложностей, чем учащиеся контрольной группы. Так среди выборки нормотипичных школьников выделено 64\% учащихся, которые боятся демонстрировать свои знания и испытывают неприязнь к учебному процессу, а среди детей-мигрантов только 9\%. Можно выделить факторы, где все группы обучающихся демонстрируют снижение с небольшой разницей в показателях: отклонение в «поведении» не превышает показатель $14 \%$ в общей выборке, причем дети-мигранты продемонстрировали наибольший процент (91\%) соответствия поведения требованиям взрослых; по показателю «интеллект, принятие ситуации в школе» низкий уровень самоотношения испытывают от 7\% до 21\% учащихся, но набольшие сложности у группы учащихся с ОВ3; по фактору «внешность и физическая привлекательность» наибольшую степень неудовлетворенности своими физическими качествами продемонстрировала группа одаренных учащихся (32\%), что является неблагоприятным признаком и может оказывать влияние на общую самооценку учащихся. Следует отметить, что среди анкетируемых детей-мигрантов и учащихся с ОВ3 0\% обучающихся акцентируют внимание на своих физических данных и испытывают по поводу своей внешности закомплексованность. Также дети-мигранты продемонстрировали высокую степень удовлетворенности своим положением в семье (100\%). Среди остальных респондентов можно выделить учащихся неудовлетворенность своим положением в семье в границах 5\%-9\%, что не является критичным показателем в общей выборке исследуемых. Среди респондентов, относящихся к группе риска по социальной неблагополучности выявлен наибольший процент учащихся с высоким уровнем тревожности (22\%) и неуверенности в себе (88\%), что на 52\% превышает показатель контроль- ной группы. Среди выборки испытуемых с ОВ3 14\% учащихся имеют проблемное поведение, 21\% испытывают негативное отношение к школе и 43\% испытывают чувство неуверенности в себе. При анализе данных по выборке одаренных учащихся $28 \%$ оценили ситуацию своего пребывания в школе, как неблагоприятную, что является показателем негативного восприятия школьной ситуации, отсутствия индивидуального подхода к образовательным потребностям обучающихся, 12\% учащихся продемонстрировали высокий уровень тревожности. Высокий показатель неуверенности в себе испытуемые с особыми образовательными потребностями продемонстрировали в границах 43\%-88\%, исключение составили одаренные учащиеся (только 4\%), что требует изменения стратегий психолого-педагогического сопровождения учащихся в школе.

На основе анализа суммарных результатов ответов респондентов нами выявлен «уровень самоотношения» учащихся, который позволяет определить способности личности школьника к самоанализу: своих эмоций, взаимоотношений с людьми, своих потребностей в соответствии с «хочу» и «должен». Уровень самоотношения, соответствующий социальному нормативу продемонстрировали 21\% обучающихся с ОВ3, 12\% одаренных школьников, 0\% детей-мигрантов, 23\% социально неблагополучных учащихся, 21\% нормотипичных школьников. Учащиеся высказали мнение, что «нравятся себе такими, какие они есть», считают себя эрудированными людьми, которые пользуются уважением среди сверстников. Положительным ответом на утверждение: «Я хорошо сплю», учащиеся продемонстрировали низкий уровень тревожности при выборе индивидуального стиля пове- 
дения, из чего следует отметить хороший уровень развития регулятивного компонента самосознания и эмоционально-ценностного отношения к себе. Низкий уровень самоотношения продемонстрировали 7\% обучающихся с ОВ3, 16\% одаренных школьников, 45\% детей-мигрантов, 23\% социально неблагополучных учащихся, относящихся к группе риска 9\% нормотипичных школьников. Низкий уровень самоотношения может впоследствии оказать деструктивное влияние на развитие личности. Через согласие с такими утверждениями, как «Мои одноклассники смеются надо мной», «Сверстники не уважают меня, не считаются со мной», «Я хотел бы быть другим», респонденты демонстрируют низкий уровень самоуважения учащихся и ожидание проявлений антипатии со стороны других, что можно охарактеризовать как пессимистичное отношение к своему социальному будущему и неверие в получении социального признания. Соглашаясь с утверждениями: «Я ненавижу школу», «Я часто ввязываюсь в драку», «Дома я плохо себя веду», обучающиеся готовы сделать демонстративный вызов социальным нормам, что затрудняет процесс социализации. При сравнительном анализе на гистограмме видно, что среди всех обучающихся с особыми образовательными потребностями по сравнению с контрольной группой наблюдается снижение уровня самоотношения в границах 50\%-73\%, что свидетельствует о нарушении целостности эмоционально-ценностного самосознания, как условия его самоопределения и саморазвития. В ролевых отношениях низкий уровень самоотношения может реализоваться как неверие в возможности своего социального возвышения, как пессимистический взгляд в будущее, интеллектуально-физическая пассивность, отрицание и даже разрушение ценностей как идеальных социальных объектов. Низкий уровень самоотношения равносилен личностному разрушению, что повышает риски десоциализации учащихся.

В результате нашего исследования выявлены факторы психосоциального неблагополучия, связанные прежде всего с пребыванием учащихся в среде школы. Это подтверждает зависимость между ситуацией психосоциального неблагополучия, существующей сегодня в образовательных учреждениях [2], [6] и проблемами в самоактуализации, самореализации и коммуникации учащихся с особыми образовательными потребностями. Негативные переживания учащихся (50\%-73\%) прежде всего связаны с неудовлетворенной потребностью в учете индивидуальных особенностей их познавательной деятельности в условиях школьного образования и потребности в позитивном взаимодействии со сверстниками вне учебного процесса. Анализ полученных данных позволил определить для каждой из групп учащихся с особыми образовательными потребностями маркеры проблемных областей в психосоциальном развитии, взаимодействии с школьной средой, что в дальнейшем может стать стратегией педагогической работы с гетерогенной группой обучающихся.

\section{Выводы}

В результате нашего исследования выявлена необходимость обеспечения индивидуальной направленности педагогического сопровождения учащихся с особыми образовательными потребностями в школе, также необходимость включения педагогов в организацию пространства общения обучающихся во внеурочное время. Так для одаренных учащихся необходима разработка индивидуальных образовательных маршрутов, обеспечивающих творческую самореализацию и самосовершенствование, расширение круга общения. Для обучающихся с ограниченными возможностями здоровья необходимо создавать условия для преодоления социальной изоляции, полноценного развития и самореализации личности школьника с последующей интеграцией в общество. Для детей-мигрантов необходима разработка индивидуальных образовательных маршрутов по овладению коммуникативно-языковой и правовой грамотностью, осмыслению своих возможностей в новых социально-культурных условиях, повышению социальной компетенции. Для социально-неблагополучных детей необходима разработка индивидуальных маршрутов, ориентированных на моделирование ситуаций личностного успеха и достижений, направленных на укрепление положительного отношения к себе и к своему будущему, предоставление возможности выбора своей социальной роли в формировании жизненных и профессиональных планов. Это позволяет сделать вывод, что для обеспечения условий социализации учащихся с особыми образовательными потребностями, образовательным учреждениям необходимо использовать практики социального партнерства с различными организациями для расширения образовательного пространства.

\section{ЛИТЕРАТУРА}

1. Исаев Е.И., Слободчиков В.И., Психология образования человека: Становление субъектности в образовательных процессах. - М.: Изд-во ПСтГУ, 2014. - 432с.

2. Качимская А.Ю. Безопасность личности в образовании и ее психологическое сопровождение // Интернетжурнал «Мир науки», 2018 №4. [Электронный ресурс]. Режим доступа: https://mir-nauki.com/PDF/26PSMN418.pdf

3. Прихожан А.М. Диагностика личностного развития детей подросткового возраста. М., 2007. - 56 с.

4. Сайт Министерства просвещения Российской Федерации. Режим доступа: https://edu.gov.ru 
5. Саламанкская Декларация и рамки действий по образованию лиц с особыми потребностями. Саламанка, Испания, 1994 г [Электронный ресурс]. Режим доступа: http://www.un.org/ru/documents/decl_conv/declarations/pdf/salamanka.pdf

6. Смык Ю.В. Инкультурация как механизм самомоделирования ребенком психологически безопасной социальной среды // Интернет-журнал «Мир науки» 2017, Том 5, №4. [Электронный ресурс]. Режим доступа: http://mir-nauki.com/PDF/33PSMN417.pdf

7. Сухомлинский В.А. Мудрая власть коллектива. М.: Молодая гвардия, 1975. - 238 с.

(с) Котикова Оксана Валентиновна (kotikox@mail.ru).

Журнал «Современная наука: актуальные проблемы теории и практики»

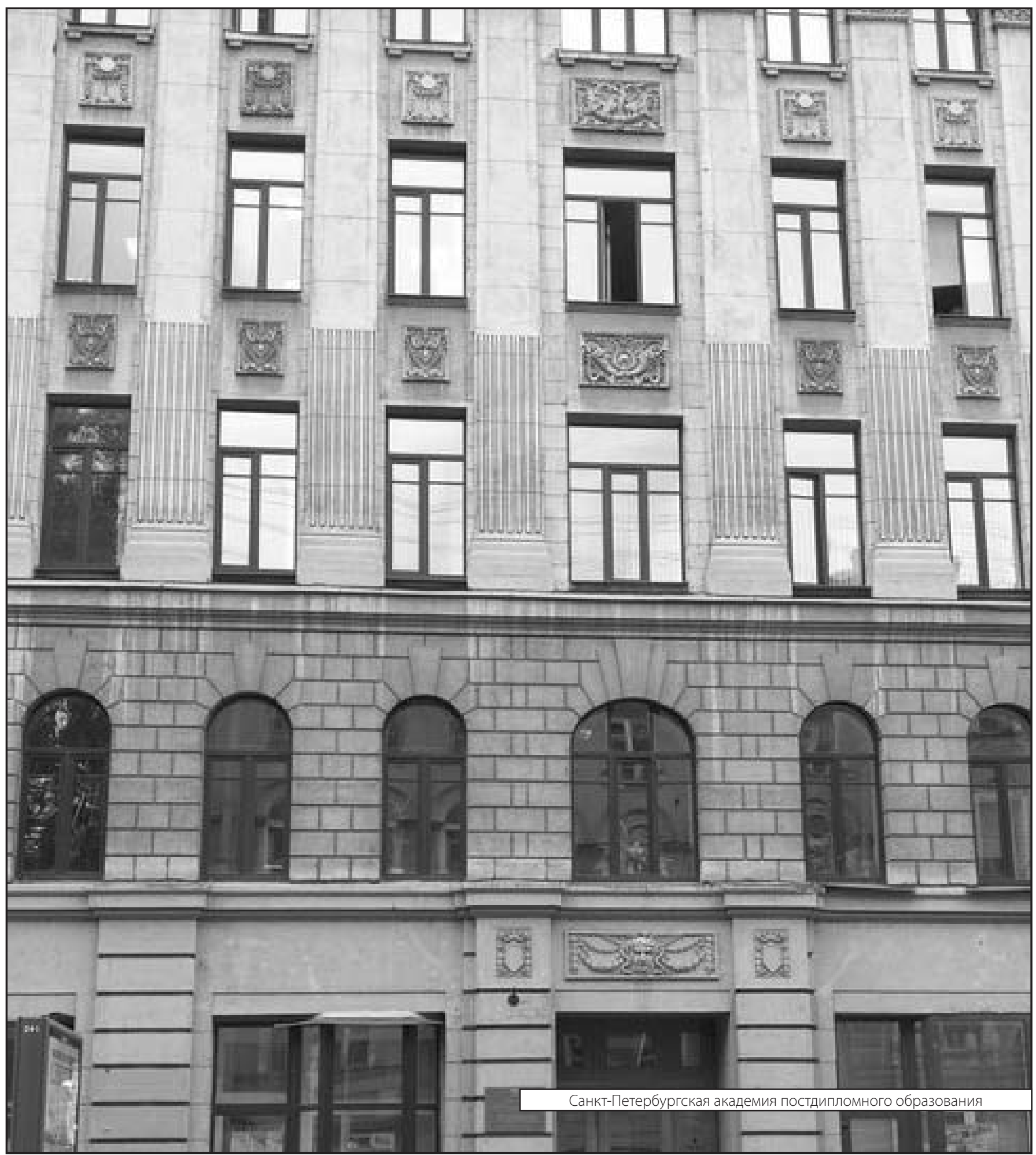

